\title{
Facile Hydrothermal Synthesis of Two-Dimensional Porous ZnO Nanosheets for Highly Sensitive Ethanol Sensor
}

\author{
Lai Van Duy, ${ }^{1}$ Nguyen Hong Hanh $\mathbb{D}^{1},{ }^{1}$ Dang Ngoc Son, ${ }^{1}$ Pham Tien Hung, \\ Chu Manh Hung $\mathbb{D}^{1},{ }^{1}$ Nguyen Van Duy, ${ }^{1}$ Nguyen Duc Hoa ${ }^{\mathbb{D}},{ }^{1}$ and Nguyen Van Hieu, \\ ${ }^{1}$ International Training Institute for Materials Science (ITIMS), Hanoi University of Science and Technology (HUST), \\ No. 1 Dai Co Viet, Hai Ba Trung, Hanoi, Vietnam \\ ${ }^{2}$ Physics Faculty, Le Quy Don Technical University, No. 236 Hoang Quoc Viet street, Cau Giay District, Hanoi, Vietnam \\ ${ }^{3}$ Faculty of Electrical and Electronic Engineering, Phenikaa Institute for Advanced Study (PIAS), Phenikaa University, Yen Nghia, \\ Ha-Dong District, Hanoi 10000, Vietnam \\ ${ }^{4}$ Phenikaa Research and Technology Institute (PRATI), A\&A Green Phoenix Group, 167 Hoang Ngan, Hanoi 10000, Vietnam
}

Correspondence should be addressed to Chu Manh Hung; mhchu@itims.edu.vn and Nguyen Duc Hoa; ndhoa@itims.edu.vn

Received 19 July 2019; Accepted 28 September 2019; Published 11 November 2019

Guest Editor: Fei Ke

Copyright (c) 2019 Lai Van Duy et al. This is an open access article distributed under the Creative Commons Attribution License, which permits unrestricted use, distribution, and reproduction in any medium, provided the original work is properly cited.

Two-dimensional porous $\mathrm{ZnO}$ nanosheets were synthesized by a facile hydrothermal method for ethanol gas-sensing application. The morphology, composition, and structure of the synthesized materials were characterized by scanning electron microscopy, energy-dispersive X-ray spectroscopy, powder X-ray diffraction, and high-resolution transmission electron microcopy. Results showed that the synthesized $\mathrm{ZnO}$ materials were porous nanosheets with a smooth surface and a thickness of $100 \mathrm{~nm}$ and a large pore size of approximately $80 \mathrm{~nm}$. The as-prepared nanosheets, which had high purity, high crystallinity, and good dispersion, were used to fabricate a gas sensor for ethanol gas detection at different operating temperatures. The porous $\mathrm{ZnO}$ nanosheet gas sensor exhibited a high response value of 21 toward $500 \mathrm{ppm}$ ethanol at a working temperature of $400^{\circ} \mathrm{C}$ with a reversible and fast response to ethanol gas $(12 \mathrm{~s} / 231 \mathrm{~s})$, indicating its potential application. We also discussed the plausible sensing mechanism of the porous $\mathrm{ZnO}$ nanosheets on the basis of the adopted ethanol sensor.

\section{Introduction}

Semiconductor metal oxide materials are drawing considerable attention for the development of sensors toward applications in numerous fields, such as air quality control, environmental monitor, and public safety from hazardous gases (e.g, $\mathrm{NO}_{\mathrm{x}}, \mathrm{SO}_{\mathrm{x}}, \mathrm{CO}_{\mathrm{x}}$, and $\mathrm{H}_{2} \mathrm{~S}$ ) [1-6]. Substantial effort has also been devoted to the fabrication of metal oxide-based gas sensors for volatile organic compound (VOC) monitoring, such as benzene, toluene, acetone, methanol, and ethanol [7-11]. Studies have been attempting to adjust the properties of these gas-sensitive nanomaterials and to form new multifunctional nanostructures. Such nanostructures and/or quantum dots exhibit many attractive features, such as high chemical and thermal stability, large surface area, adjustable electronic state, quantum confinement, high electron mobil- ity, and excellent catalytic properties [11, 12]. Different types of metal oxide nanostructures such as tin oxide $\left(\mathrm{SnO}_{2}\right)$, indium oxide $\left(\operatorname{In}_{2} \mathrm{O}_{3}\right)$, zinc oxide $(\mathrm{ZnO})$, tungsten trioxide $\left(\mathrm{WO}_{3}\right)$, cobalt oxide $\left(\mathrm{Co}_{3} \mathrm{O}_{4}\right)$, nickel oxide $(\mathrm{NiO})$, and titanium oxide $\left(\mathrm{TiO}_{2}\right)$ have been discovered for gas-sensing applications [4, 10, 13-17]. $\mathrm{ZnO}$ is a potential sensing material because of its outstanding properties; it is an environmentally friendly $\mathrm{n}$-type semiconductor that has a direct and wide band gap of $3.37 \mathrm{eV}$, interenergy large exciton at room temperature $(\sim 60 \mathrm{meV})$, high thermal and chemical stability, high electronic mobility, ease of synthesis, low cost, high sensitivity to target gases, and large surface-to-volume ratio $[10,17,18]$. Extensive studies have been focused on the development of gas sensors based on $\mathrm{ZnO}$ nanostructures with various morphologies and composition for the detection of VOCs [19-21]. ZnO can reportedly be prepared on a large 


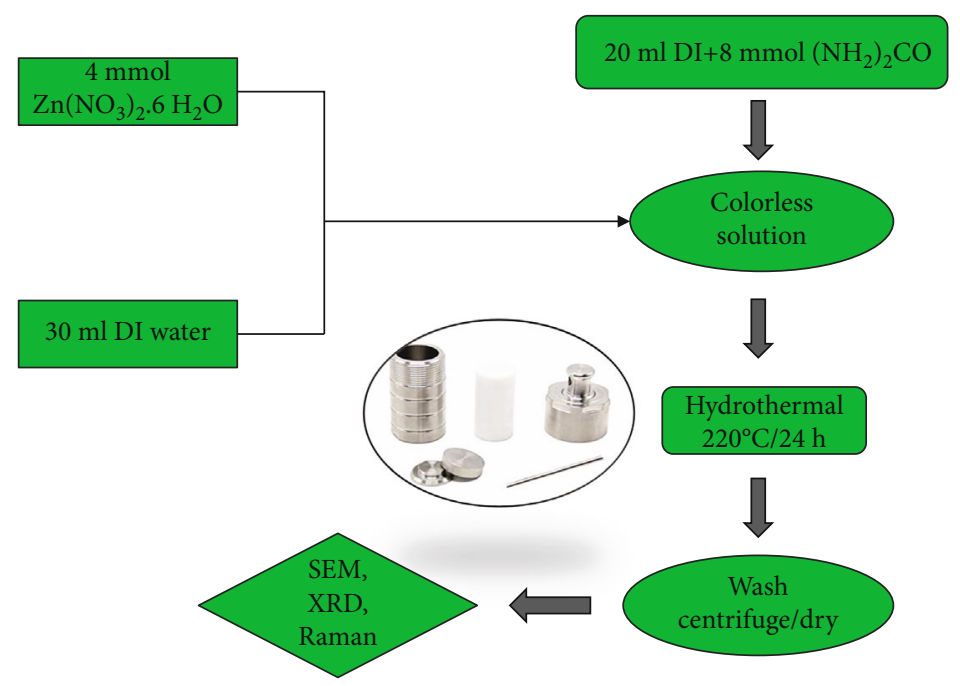

Figure 1: Hydrothermal synthesis process of porous $\mathrm{ZnO}$ nanosheets.

scale by using simple wet chemical glands as hydrothermal $[17,22]$, coprecipitation [23], sol-gel [24], electrospinning [25], thermal evaporation [26], and electrodeposition methods [27]. By utilizing the hydrothermal method, researchers can create a huge number of shapes and structures of this material $[17,22]$, which has a large surfaceto-volume ratio, for use in different fields. However, an easy synthesis of porous $\mathrm{ZnO}$ nanosheets for gas sensor applications remains challenging.

In this study, we develop a simple hydrothermal method for synthesizing porous $\mathrm{ZnO}$ nanosheets for effective ethanol gas sensing in industry applications. Porous $\mathrm{ZnO}$ nanosheets possess a large specific surface area for gas adsorption because of its porous structure, thus showing superior sensitivity to ethanol.

\section{Materials and Methods}

Porous $\mathrm{ZnO}$ nanosheets were synthesized via a hydrothermal method followed by annealing at $600^{\circ} \mathrm{C}$. The synthesis processes of the porous $\mathrm{ZnO}$ nanosheets are summarized in Figure 1, which was adapted from the literature $[28,29]$ with modification. In a typical synthesis, zinc nitrate hexahydrate $\left(\mathrm{Zn}\left(\mathrm{NO}_{3}\right)_{2} \cdot 6 \mathrm{H}_{2} \mathrm{O}\right)(4 \mathrm{mmol})$ was dissolved in $30 \mathrm{~mL}$ deionized water. After this solution was stirred for $15 \mathrm{~min}, 20 \mathrm{~mL}$ urea $\left(\mathrm{CH}_{4} \mathrm{~N}_{2} \mathrm{O}\right)(8 \mathrm{mmol})$ solution was added with further stirring for $15 \mathrm{~min}$ to adjust the $\mathrm{pH}$ to 5 . The above turbid solution was transferred into a $100 \mathrm{~mL}$ Teflon-lined stainless steel autoclave for hydrothermal. The hydrothermal process was maintained at $220^{\circ} \mathrm{C}$ for $24 \mathrm{~h}$. After being natural cooled to room temperature, the precipitate was centrifuged and washed with deionized water several times. Then, it was washed twice using an ethanol solution and collected by centrifugation at $4000 \mathrm{rpm}$. Finally, the white product was obtained and dried in an oven at $60^{\circ} \mathrm{C}$ for $24 \mathrm{~h}$. The synthesized materials were characterized by field-emission scanning electron microscopy (SEM, JEOL 7600F), powder X-ray diffraction (XRD; Advance D8, Bruker), energy-dispersive
X-ray spectroscopy (EDS), and high-resolution transmission electron microscopy (HRTEM, Tecnai G2F20STWIN, Philips). The synthesized porous $\mathrm{ZnO}$ nanosheets were then characterized sensing properties using a labmade gas-sensing system [30].

\section{Results and Discussion}

Figures 2(a) and 2(b) show the SEM images of the grown material after it was calcined at $600^{\circ} \mathrm{C}$ for $2 \mathrm{~h}$. The lowmagnification SEM image (Figure 2(a)) demonstrates that the as-prepared products are composed of homogeneous nanosheets with porous structure. The high-magnification SEM image (Figure 2(b)) reveals that the synthesized nanosheets are nanosized porous architectures comprising sheet nanostructures with edge thicknesses of about $100 \mathrm{~nm}$. Moreover, many small, round holes about $80 \mathrm{~nm}$ in diameter are evenly distributed on the surface. The large surface-tovolume ratio of nanosheets may provide large sites for gaseous-molecule adsorption, thereby enhancing the gassensing performance [4]. Herein, the homogenous nanosheets were obtained without using any surfactant, thus reducing the usage of chemicals. Zinc nitrate hexahydrate was used as a $\mathrm{Zn}^{2+}$ precursor, whereas the urea was utilized as media to control the solution $\mathrm{pH}$. Urea was easily decomposed into $\mathrm{NH}_{3}$ and HNCO during the hydrothermal process. Thus, it reacted with $\mathrm{Zn}^{2+}$ to form $\mathrm{ZnO}$ and generate the porous structure.

The crystal structure of the synthesized nanosheets was studied by XRD, and the data are shown in Figure 3(a). The main diffraction peaks are indexed to the (100), (002), (101), (102), (110), (103), (200), (112), (201), and (202) lattice planes of $\mathrm{ZnO}$. All the diffraction peaks correspond to wurtzite $\mathrm{ZnO}$ (JCPDS card No. 36-1451) without other observable impurity characteristic peaks; therefore, highpurity $\mathrm{ZnO}$ can be obtained using the solvothermal method combined with calcination [10, 17]. The EDS analysis indicates the presence of $\mathrm{Zn}$ and $\mathrm{O}$ elements from the nanosheets 


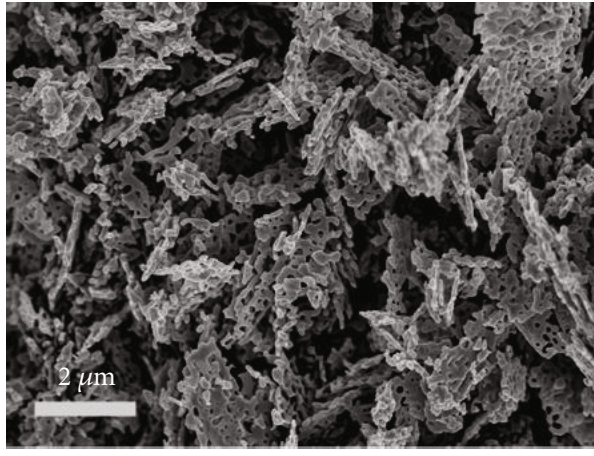

(a)

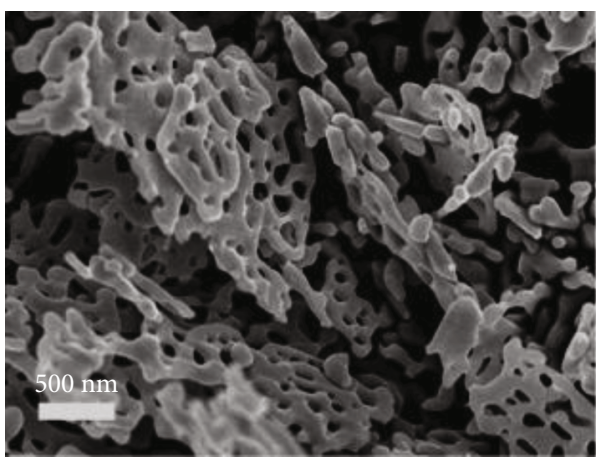

(b)

FIGURE 2: (a) Low- and (b) high-magnification SEM images of synthesized porous ZnO nanosheets.

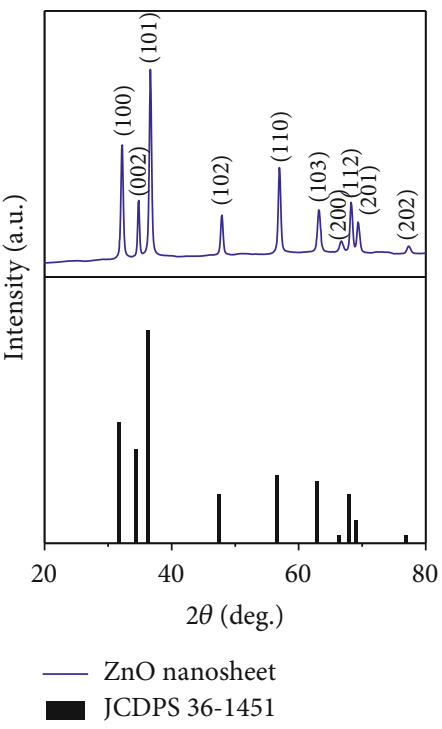

(a)

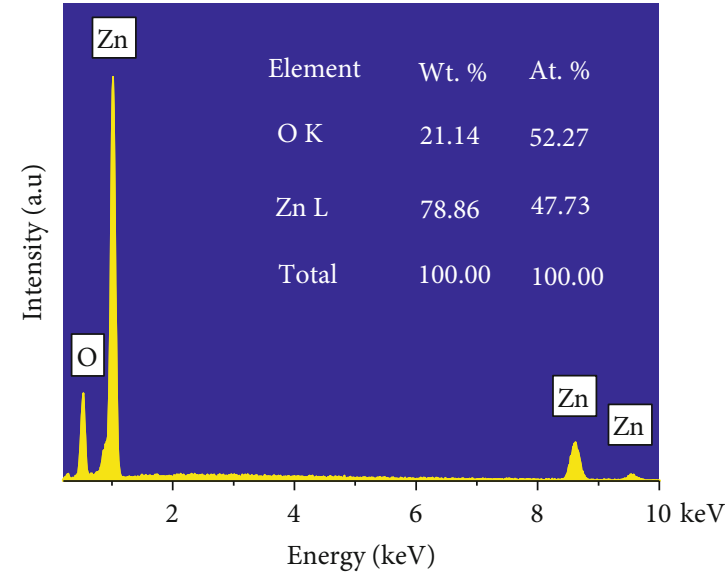

(b)

Figure 3: (a) XRD pattern and (b) EDS spectrum of the synthesized $\mathrm{ZnO}$ nanosheets annealed at $600^{\circ} \mathrm{C}$ for $2 \mathrm{~h}$ in air.

(Figure 3(b)). The synthesized nanosheets have no impurity and are thus of high quality. The $\mathrm{O}$ and $\mathrm{Zn}$ compositions estimated from the EDX analysis are 52.27 at.\% and 47.74 at.\%, respectively. This composition is approximately the stoichiometry $\mathrm{ZnO}[9]$.

The atomic structure of the porous $\mathrm{ZnO}$ nanosheets was investigated by HRTEM images and the selected area electron diffraction (SAED) patterns. Figure 4(a) shows a representative low magnification TEM image of the $\mathrm{ZnO}$ nanosheets taken on the red square region of the inset. It exhibits a smooth surface and the porous structure of the synthesized nanosheets, which confirm the results obtained from the SEM images. Figure 4(b) reveals a representative high magnification TEM image captured on the yellow square area of Figure 4(a). The image shows a well-defined lattice fringe separation with a lattice spacing of $0.52 \mathrm{~nm}$, indicating a periodic $\mathrm{ZnO}$ lattice growth along the (001) plane. The inset of Figure 4(b) shows the corresponding
SAED pattern obtained from the lattice fringes of the $\mathrm{ZnO}$ nanosheets, confirming that the synthesized $\mathrm{ZnO}$ has the single crystalline wurtzite structure growing along the [0001] direction [31].

The transient resistance versus time upon exposure to different concentrations of $\mathrm{C}_{2} \mathrm{H}_{5} \mathrm{OH}$ measured at temperatures ranging from $250^{\circ} \mathrm{C}$ to $400^{\circ} \mathrm{C}$ is shown in Figures 5(a)-5(d). Clearly, the sensor response value initially increases and then decreases with increased operating temperature. The maximum response for ethanol is 21 at the optimum operating temperature of $400^{\circ} \mathrm{C}$. The sensor response $S\left(R_{\mathrm{a}} / R_{\mathrm{g}}\right)$, as a function of $\mathrm{C}_{2} \mathrm{H}_{5} \mathrm{OH}$ concentrations measured at different temperatures, is shown in Figure 5(b).

At all measured temperatures, the sensor response increases with increased $\mathrm{C}_{2} \mathrm{H}_{5} \mathrm{OH}$ concentration in the measured range. At a given concentration, the sensor response increases with increased working temperature. However, increasing the working temperature requires a 

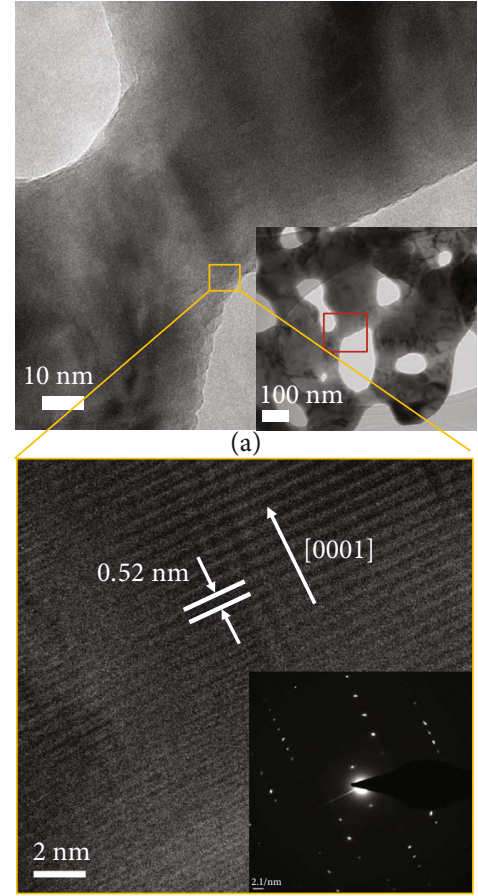

(b)

Figure 4: (a) Low and (b) high magnification TEM images of the porous $\mathrm{ZnO}$ nanosheet. Inset of (b) shows SAED pattern.

considerable amount of energy, which can damage microheaters. For practical applications, the power consumption of the device should be limited; thus, the sensor response at temperatures higher than $450^{\circ} \mathrm{C}$ did not need to be characterized.

The gas-sensing mechanism of metal oxide is based on the adsorption and desorption of gas molecules and chemical reactions on the surface of sensing materials $[10,32]$. Herein, band diagrams of nanoporous $\mathrm{ZnO}$ nanosheet in air and in ethanol are shown in Figure 6 to explain the gas-sensing mechanism. $\mathrm{ZnO}$ is a well-known n-type conductor. When the sensor is exposed to air, oxygen molecules originating from the atmosphere adsorb onto the $\mathrm{ZnO}$ surface and then ionize to negative oxygen species via trapping free electrons from the conduction band, as shown in Equations (1)-(3).

$$
\begin{array}{r}
\mathrm{O}_{2}(\text { gas }) \longrightarrow \mathrm{O}_{2}(\text { ads }) \\
\mathrm{O}_{2}(\text { ads })+\mathrm{e}-\longrightarrow \mathrm{O}^{2-}(\text { ads }) \\
\mathrm{O}^{2-}(\text { ads })+\mathrm{e}-\longrightarrow 2 \mathrm{O}^{-}(\text {ads })
\end{array}
$$

When reductive $\mathrm{C}_{2} \mathrm{H}_{5} \mathrm{OH}$ gas vapour approaches to the sensor, it reacts with the adsorbed oxygen species on the $\mathrm{ZnO}$ sheets. Consequently, the captured electrons will be released to the $\mathrm{ZnO}$, ultimately decreasing the surface depletion layer and the sensor resistance. The reaction process

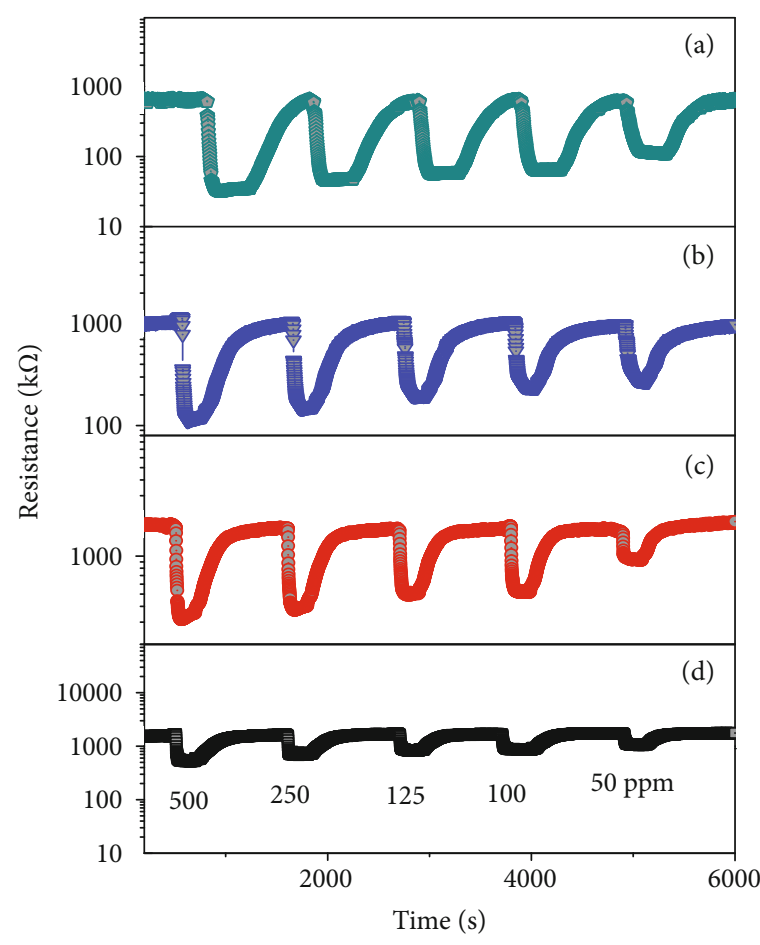

$$
\begin{aligned}
& -\square @ \mathrm{C}_{2} \mathrm{H}_{5} \mathrm{OH} \& 400^{\circ} \mathrm{C}-\odot-@ \mathrm{C}_{2} \mathrm{H}_{5} \mathrm{OH} \& 300^{\circ} \mathrm{C} \\
& -\nabla-@ \mathrm{C}_{2} \mathrm{H}_{5} \mathrm{OH} \& 350^{\circ} \mathrm{C}-\square-@ \mathrm{C}_{2} \mathrm{H}_{5} \mathrm{OH} \& 250^{\circ} \mathrm{C}
\end{aligned}
$$

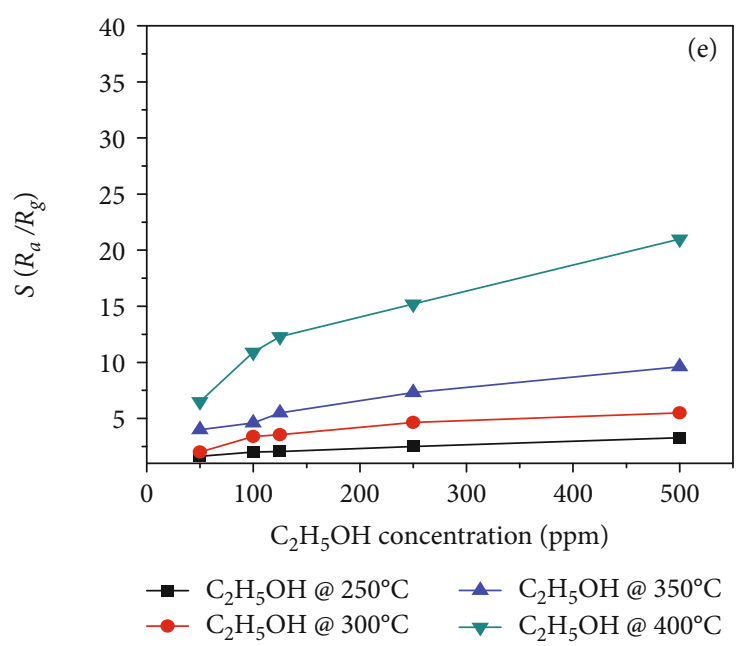

FIgURE 5: $\mathrm{C}_{2} \mathrm{H}_{5} \mathrm{OH}$ sensing characteristics of porous $\mathrm{ZnO}$ nanosheets measured at different operating temperatures: transient resistance versus time upon exposure to different $\mathrm{C}_{2} \mathrm{H}_{5} \mathrm{OH}$ concentrations at $450^{\circ} \mathrm{C}(\mathrm{a}), 400^{\circ} \mathrm{C}$ (b), $350^{\circ} \mathrm{C}$ (c), and $250^{\circ} \mathrm{C}$ (d); (e) gas response as a function of $\mathrm{C}_{2} \mathrm{H}_{5} \mathrm{OH}$ concentration.

between the surface-adsorbed oxygen species and ethanol is described by Equations (4)-(6).

$$
\begin{gathered}
\mathrm{C}_{2} \mathrm{H}_{5} \mathrm{OH}+36 \mathrm{O}_{2}^{-} \longrightarrow 2 \mathrm{CO}_{2}+3 \mathrm{H}_{2} \mathrm{O}+3 \mathrm{e}^{-} \\
\mathrm{C}_{2} \mathrm{H}_{5} \mathrm{OH}+6 \mathrm{O}^{-} \longrightarrow 2 \mathrm{CO}_{2}+3 \mathrm{H}_{2} \mathrm{O}+6 \mathrm{e}^{-} \\
\mathrm{C}_{2} \mathrm{H}_{5} \mathrm{OH}+6 \mathrm{O}^{-} \longrightarrow 2 \mathrm{CO}_{2}+3 \mathrm{H}_{2} \mathrm{O}+12 \mathrm{e}^{-}
\end{gathered}
$$




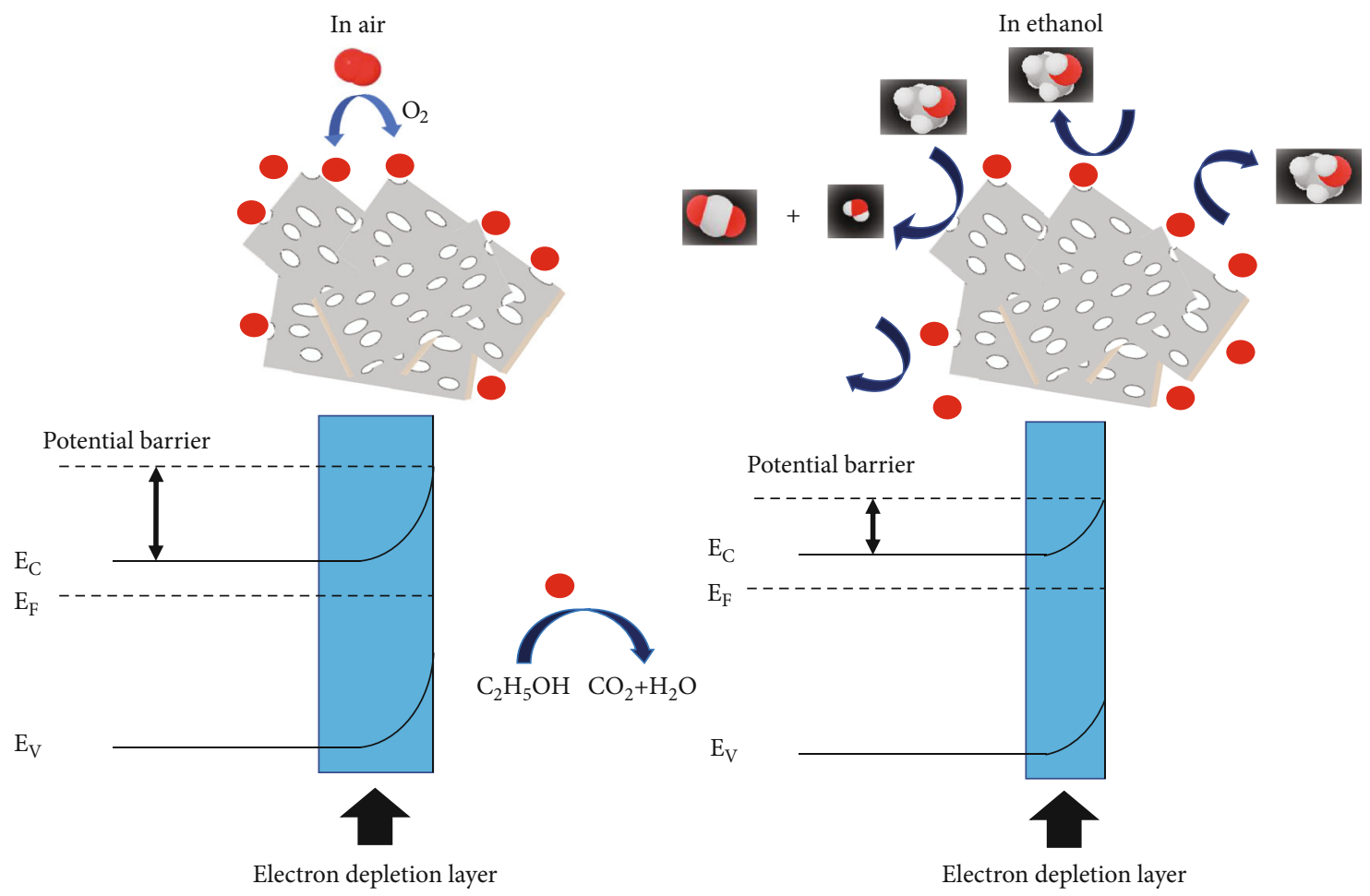

Figure 6: Schematic of the $\mathrm{C}_{2} \mathrm{H}_{5} \mathrm{OH}$ gas-sensing mechanism of the nanoporous $\mathrm{ZnO}$.

TABLE 1: Comparison of different $\mathrm{ZnO}$ nanosheet-based VOC gas sensors.

\begin{tabular}{|c|c|c|c|c|c|}
\hline Materials & Gas & $C(\mathrm{ppm})$ & Response & $T\left({ }^{\circ} \mathrm{C}\right)$ & Ref. \\
\hline $\mathrm{ZnO} \mathrm{NPs}$ & Ethanol & 100 & 5 & 350 & {$[33]$} \\
\hline $\mathrm{Au}-\mathrm{ZnO} \mathrm{NWs}$ & Ethanol & 50 & 7 & 325 & {$[34]$} \\
\hline $\mathrm{ZnO} N F s$ & Ethanol & 100 & 6 & 340 & {$[35]$} \\
\hline ZnO NFs & Acetone & 100 & 4 & 360 & {$[35]$} \\
\hline Sn doped $\mathrm{ZnO}$ NSs & Acetone & 200 & 5.55 & 320 & {$[36]$} \\
\hline $\mathrm{ZnO}$ nanoplate & Chlorobenzene & 100 & 2 & 400 & [37] \\
\hline Porous $\mathrm{ZnO}$ NSs & Ethanol & 100 & 11 & 400 & This work \\
\hline Porous $\mathrm{ZnO}$ NSs & Ethanol & 500 & 21 & 400 & This work \\
\hline
\end{tabular}

Given the porous structure of the nanosheets, gas molecules can easily adsorb onto the total surface of the $\mathrm{ZnO}$ nanosheet and significantly change the depletion region, thus maximizing the sensing performance [13].

Comparative results of the fabricated sensor with those in other reports are summarized in Table 1 . The porous $\mathrm{ZnO}$ nanosheets produced the highest response value to ethanol, followed by the Au-modified $\mathrm{ZnO}$ nanowires, $\mathrm{ZnO}$ nanofibers, and $\mathrm{ZnO}$ nanoparticles. The sensor also showed a higher response value for ethanol gas compared with acetone and chlorobenzene. However, the porous $\mathrm{ZnO}$ nanosheets operated at a relatively higher working temperature. The high working temperature and low sensitivity of the sensor limited its potential application. Therefore, the controlled synthesis of highly sensitive ethanol sensors that operate at low temperatures is mandatory for future sensor applications.
The gas selectivity of the porous $\mathrm{ZnO}$ nanosheet sensor was tested to various gases, namely, $\mathrm{CH}_{3} \mathrm{OH}, \mathrm{C}_{6} \mathrm{H}_{5} \mathrm{CH}_{3}$, and $\mathrm{NH}_{3}$, at $400^{\circ} \mathrm{C}$ with a gas concentration of $500 \mathrm{ppm}$, as shown in Figure $7(\mathrm{a})$. The data show that the response of the nanoporous $\mathrm{ZnO}$ sensor to $500 \mathrm{ppm} \mathrm{C}_{2} \mathrm{H}_{5} \mathrm{OH}$ is much higher than that of the sensors to other gases at the same concentration and working temperature. This finding indicates good selectivity of the porous $\mathrm{ZnO}$ nanosheet sensor to $\mathrm{C}_{2} \mathrm{H}_{5} \mathrm{OH}$ gas. Figure 7 (b) reveals the short-term stability of the porous $\mathrm{ZnO}$ nanosheet sensor with 10 response/recovery cycles to $125 \mathrm{ppm}_{2} \mathrm{H}_{5} \mathrm{OH}$ at $400^{\circ} \mathrm{C}$. The sensor can noticeably maintain its initial response amplitude with 10 continuous response/recovery cycles. These results indicate that the sensor has good selectivity, reproducibility, and short-term stability, which are important characteristics of gas sensors for practical applications. 


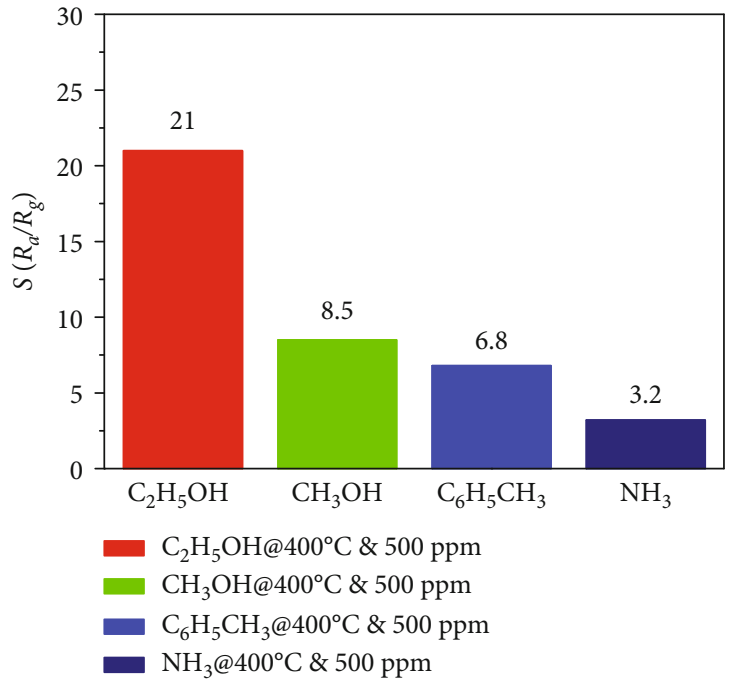

(a)

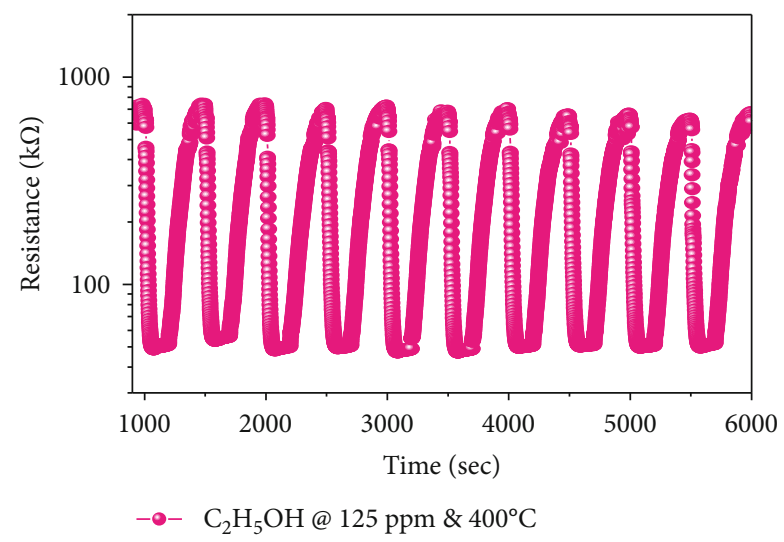

(b)

Figure 7: (a) Selectivity to various gases at $400^{\circ} \mathrm{C}$ and stability at $125 \mathrm{ppm} \mathrm{C}_{2} \mathrm{H}_{5} \mathrm{OH}$ gas at $400^{\circ} \mathrm{C}$ of the nanoporous $\mathrm{ZnO}$ nanosheetbased sensors.

\section{Conclusions}

We introduced an easy and scalable hydrothermal synthesis of nanoporous $\mathrm{ZnO}$ nanosheets for effective $\mathrm{C}_{2} \mathrm{H}_{5} \mathrm{OH}$ gassensing applications. The obtained porous nanosheets performed good crystallinity and dispersing levels. The mean thickness of the $\mathrm{ZnO}$ nanosheets is approximately $100 \mathrm{~nm}$, and the pore size is about $80 \mathrm{~nm}$. The obtained nanoporous $\mathrm{ZnO}$ nanosheets exhibited excellent gas-sensing properties to ethanol in terms of high and fast response and recovery times. The results show that nanoporous $\mathrm{ZnO}$ nanosheets can be a potential material for high-performance ethanol gas sensing.

\section{Data Availability}

The data used to support the findings of this study are included within the article.

\section{Conflicts of Interest}

The authors declare that there is no conflict of interest regarding the publication of this paper.

\section{Acknowledgments}

This research was funded by the Vietnam National Foundation for Science and Technology Development (NAFOSTED) under grant number 103.02-2017.15. We would like to thank Prof. Young-Woo Heo (Kyungpook National University) for his help with TEM measurement.

\section{References}

[1] P. Van Tong, N. D. Hoa, H. T. Nha, N. Van Duy, C. M. Hung, and N. Van Hieu, " $\mathrm{SO}_{2}$ and $\mathrm{H}_{2} \mathrm{~S}$ sensing properties of hydro- thermally synthesized $\mathrm{CuO}$ nanoplates," Journal of Electronic Materials, vol. 47, no. 12, pp. 7170-7178, 2018.

[2] C. M. Hung, D. T. T. Le, and N. Van Hieu, "On-chip growth of semiconductor metal oxide nanowires for gas sensors: a review," Journal of Science: Advanced Materials and Devices, vol. 2, no. 3, pp. 263-285, 2017.

[3] T. M. Ngoc, N. Van Duy, N. Duc Hoa, C. Manh Hung, H. Nguyen, and N. Van Hieu, "Effective design and fabrication of low-power-consumption self-heated $\mathrm{SnO}_{2}$ nanowire sensors for reducing gases," Sensors and Actuators B: Chemical, vol. 295, pp. 144-152, 2019.

[4] N. D. Hoa, C. M. Hung, N. Van Duy, and N. Van Hieu, "Nanoporous and crystal evolution in nickel oxide nanosheets for enhanced gas- sensing performance," Sensors and Actuators B: Chemical, vol. 273, pp. 784-793, 2018.

[5] N. D. Hoa, N. V. Duy, S. A. el-Safty, and N. V. Hieu, "Meso/nanoporous semiconducting metal oxides for gas sensor applications," Journal of Nanomaterials, vol. 2015, 14 pages, 2015.

[6] X. Li, X. Li, N. Chen et al., "CuO- $\mathrm{In}_{2} \mathrm{O}_{3}$ Core-Shell Nanowire Based Chemical Gas Sensors," Journal of Nanomaterials, vol. 2014, Article ID 973156, 7 pages, 2014.

[7] C. Su, L. Zhang, Y. Han et al., "Glucose-assisted synthesis of hierarchical flower-like $\mathrm{Co}_{3} \mathrm{O}_{4}$ nanostructures assembled by porous nanosheets for enhanced acetone sensing," Sensors and Actuators B: Chemical, vol. 288, pp. 699-706, 2019.

[8] X. Liu, K. Zhao, X. Sun, X. Duan, C. Zhang, and X. Xu, "Electrochemical sensor to environmental pollutant of acetone based on Pd- loaded on mesoporous $\mathrm{In}_{2} \mathrm{O}_{3}$ architecture," Sensors and Actuators B: Chemical, vol. 290, pp. 217-225, 2019.

[9] X. Wang, F. Chen, M. Yang et al., "Dispersed $\mathrm{WO}_{3}$ nanoparticles with porous nanostructure for ultrafast toluene sensing," Sensors and Actuators B: Chemical, vol. 289, pp. 195-206, 2019.

[10] C. T. Quy, N. X. Thai, N. D. Hoa et al., " $\mathrm{C}_{2} \mathrm{H}_{5} \mathrm{OH}$ and NO2sensing properties of $\mathrm{ZnO}$ nanostructures: correlation between 
crystal size, defect level and sensing performance," RSC Advances, vol. 8, no. 10, pp. 5629-5639, 2018.

[11] C. Su, L. Zhang, Y. Han et al., "Controllable synthesis of crescent-shaped porous $\mathrm{NiO}$ nanoplates for conductometric ethanol gas sensors," Sensors and Actuators B: Chemical, vol. 296, p. 126642, 2019.

[12] J. Zhu, F. Zhu, X. Yue et al., "Waste utilization of synthetic carbon quantum dots based on tea and peanut shell," Journal of Nanomaterials, vol. 2019, 7 pages, 2019.

[13] T. T. Le Dang, M. Tonezzer, and V. H. Nguyen, "Hydrothermal growth and hydrogen selective sensing of nickel oxide nanowires," Journal of Nanomaterials, vol. 2015, Article ID 785856, 8 pages, 2015.

[14] P. Bindra and A. Hazra, "Selective detection of organic vapors using $\mathrm{TiO}_{2}$ nanotubes based single sensor at room temperature," Sensors and Actuators B: Chemical, vol. 290, pp. 684690, 2019.

[15] D. Zhang, Y. Fan, G. Li et al., "Highly sensitive BTEX sensors based on hexagonal $\mathrm{WO}_{3}$ nanosheets," Sensors and Actuators B: Chemical, vol. 293, pp. 23-30, 2019.

[16] P. Van Tong, N. D. Hoa, N. Van Duy, V. Van Quang, N. T. Lam, and N. Van Hieu, "In-situ decoration of Pd nanocrystals on crystalline mesoporous $\mathrm{NiO}$ nanosheets for effective hydrogen gas sensors," International Journal of Hydrogen Energy, vol. 38, no. 27, pp. 12090-12100, 2013.

[17] V. T. Duoc, D. T. T. Le, N. D. Hoa et al., "New design of $\mathrm{ZnO}$ nanorod- and nanowire-based $\mathrm{NO}_{2}$ room-temperature sensors prepared by hydrothermal method," Journal of Nanomaterials, vol. 2019, Article ID 6821937, 9 pages, 2019.

[18] M. L. M. Napi, S. M. Sultan, R. Ismail, M. K. Ahmad, and G. M. T. Chai, "Optimization of a hydrothermal growth process for low resistance 1D fluorine-doped zinc oxide nanostructures," Journal of Nanomaterials, vol. 2019, Article ID 4574507, 10 pages, 2019.

[19] N. D. Khoang, D. D. Trung, N. Van Duy, N. D. Hoa, and N. Van Hieu, "Design of $\mathrm{SnO}_{2} / \mathrm{ZnO}$ hierarchical nanostructures for enhanced ethanol gas-sensing performance," Sensors and Actuators B: Chemical, vol. 174, pp. 594-601, 2012.

[20] S.-M. Li, L.-X. Zhang, M.-Y. Zhu et al., "Acetone sensing of $\mathrm{ZnO}$ nanosheets synthesized using room-temperature precipitation," Sensors and Actuators B: Chemical, vol. 249, pp. 611-623, 2017.

[21] S. Agarwal, P. Rai, E. N. Gatell et al., "Gas sensing properties of $\mathrm{ZnO}$ nanostructures (flowers/rods) synthesized by hydrothermal method," Sensors and Actuators B: Chemical, vol. 292, pp. 24-31, 2019.

[22] G. Amin, M. H. Asif, A. Zainelabdin, S. Zaman, O. Nur, and M. Willander, "Influence of $\mathrm{pH}$, precursor concentration, growth time, and temperature on the morphology of $\mathrm{ZnO}$ nanostructures grown by the hydrothermal method," Journal of Nanomaterials, vol. 2011, Article ID 269692, 9 pages, 2011.

[23] M. El-Hilo, A. A. Dakhel, and Z. J. Yacoob, "Magnetic interactions in $\mathrm{Co}^{2+}$ doped $\mathrm{ZnO}$ synthesised by co-precipitation method: efficient effect of hydrogenation on the long-range ferromagnetic order," Journal of Magnetism and Magnetic Materials, vol. 482, pp. 125-134, 2019.

[24] Y. Zeng, L. Qiao, Y. Bing et al., "Development of microstructure CO sensor based on hierarchically porous $\mathrm{ZnO}$ nanosheet thin films," Sensors and Actuators B: Chemical, vol. 173, pp. 897-902, 2012.
[25] J.-H. Kim, A. Mirzaei, H. W. Kim, P. Wu, and S. S. Kim, "Design of supersensitive and selective $\mathrm{ZnO}$-nanofiber-based sensors for $\mathrm{H}_{2}$ gas sensing by electron-beam irradiation," Sensors and Actuators B: Chemical, vol. 293, pp. 210-223, 2019.

[26] C. M. Hung, H. V. Phuong, N. Van Duy, N. D. Hoa, and N. Van Hieu, "Comparative effects of synthesis parameters on the $\mathrm{NO}_{2}$ gas-sensing performance of on-chip grown $\mathrm{ZnO}$ and $\mathrm{Zn}_{2} \mathrm{SnO}_{4}$ nanowire sensors," Journal of Alloys and Compounds, vol. 765, pp. 1237-1242, 2018.

[27] C. Wang, Z.-G. Wang, R. Xi et al., "In situ synthesis of flowerlike $\mathrm{ZnO}$ on $\mathrm{GaN}$ using electrodeposition and its application as ethanol gas sensor at room temperature," Sensors and Actuators B: Chemical, vol. 292, pp. 270-276, 2019.

[28] Z. Feng, Y. Ma, V. Natarajan, Q. Zhao, X. Ma, and J. Zhan, "Insitu generation of highly dispersed Au nanoparticles on porous $\mathrm{ZnO}$ nanoplates via ion exchange from hydrozincite for VOCs gas sensing," Sensors and Actuators B: Chemical, vol. 255, pp. 884-890, 2018.

[29] Y. Xiao, L. Lu, A. Zhang et al., "Highly enhanced acetone sensing performances of porous and single crystalline $\mathrm{ZnO}$ nanosheets: high percentage of exposed (100) facets working together with surface modification with Pd nanoparticles," ACS Applied Materials \& Interfaces, vol. 4, no. 8, pp. 37973804, 2012.

[30] K. Nguyen, C. M. Hung, T. M. Ngoc et al., "Low-temperature prototype hydrogen sensors using $\mathrm{Pd}$-decorated $\mathrm{SnO}_{2}$ nanowires for exhaled breath applications," Sensors and Actuators B: Chemical, vol. 253, pp. 156-163, 2017.

[31] W. L. Ong, H. Huang, J. Xiao, K. Zeng, and G. W. Ho, “Tuning of multifunctional cu-doped $\mathrm{ZnO}$ films and nanowires for enhanced piezo/ferroelectric-like and gas/photoresponse properties," Nanoscale, vol. 6, no. 3, pp. 1680-1690, 2014.

[32] X. Xing, Y. Yang, Z. Yan et al., "CdO-Ag-ZnO nanocomposites with hierarchically porous structure for effective VOCs gassensing properties," Ceramics International, vol. 45, no. 4, pp. 4322-4334, 2019.

[33] L. Zhu, Y. Li, and W. Zeng, "Hydrothermal synthesis of hierarchical flower-like $\mathrm{ZnO}$ nanostructure and its enhanced ethanol gas-sensing properties," Applied Surface Science, vol. 427, pp. 281-287, 2018.

[34] N. S. Ramgir, M. Kaur, P. K. Sharma et al., "Ethanol sensing properties of pure and Au modified $\mathrm{ZnO}$ nanowires," Sensors and Actuators B: Chemical, vol. 187, pp. 313-318, 2013.

[35] L. Liu, S. Li, J. Zhuang et al., "Improved selective acetone sensing properties of Co-doped $\mathrm{ZnO}$ nanofibers by electrospinning," Sensors and Actuators B: Chemical, vol. 155, no. 2, pp. 782-788, 2011.

[36] Y. Al-Hadeethi, A. Umar, S. H. Al-Heniti et al., "2D Sn-doped $\mathrm{ZnO}$ ultrathin nanosheet networks for enhanced acetone gas sensing application," Ceramics International, vol. 43, no. 2, pp. 2418-2423, 2017.

[37] Z. Jing and J. Zhan, "Fabrication and Gas-Sensing Properties of Porous ZnO Nanoplates," Advanced Materials, vol. 20, no. 23, pp. 4547-4551, 2008. 


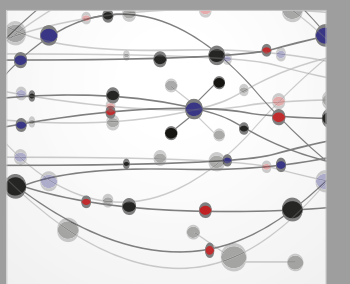

The Scientific World Journal
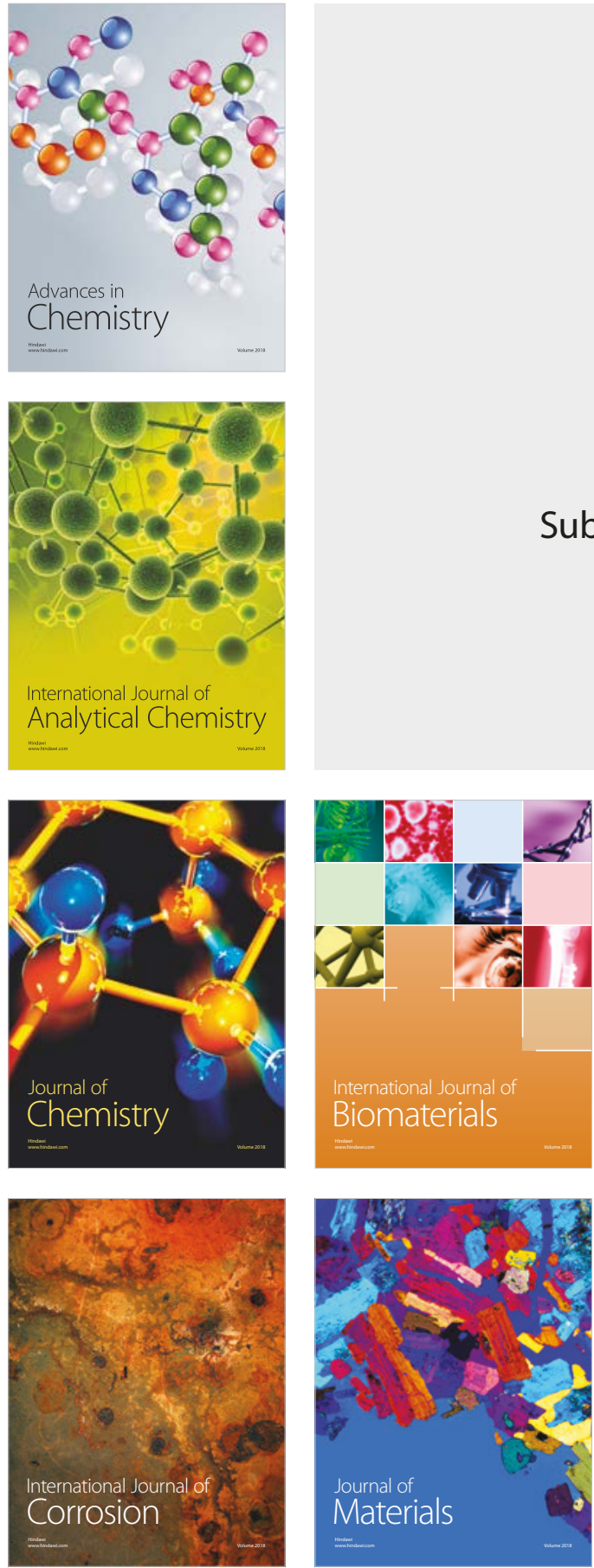

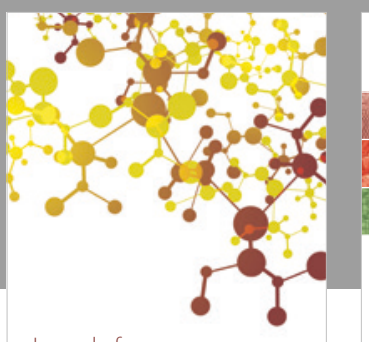

Journal of

Applied Chemistry
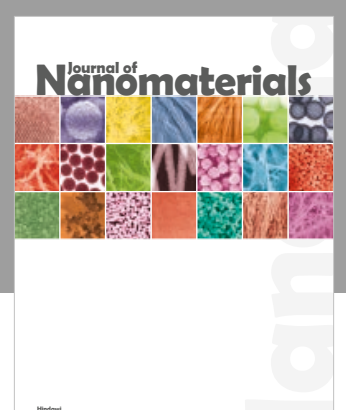

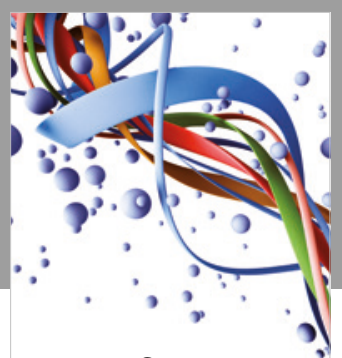

Scientifica

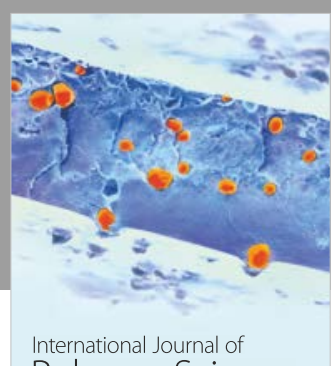

Polymer Science

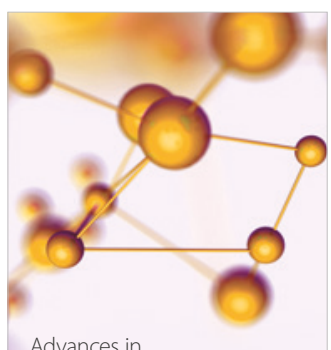

Physical Chemistry
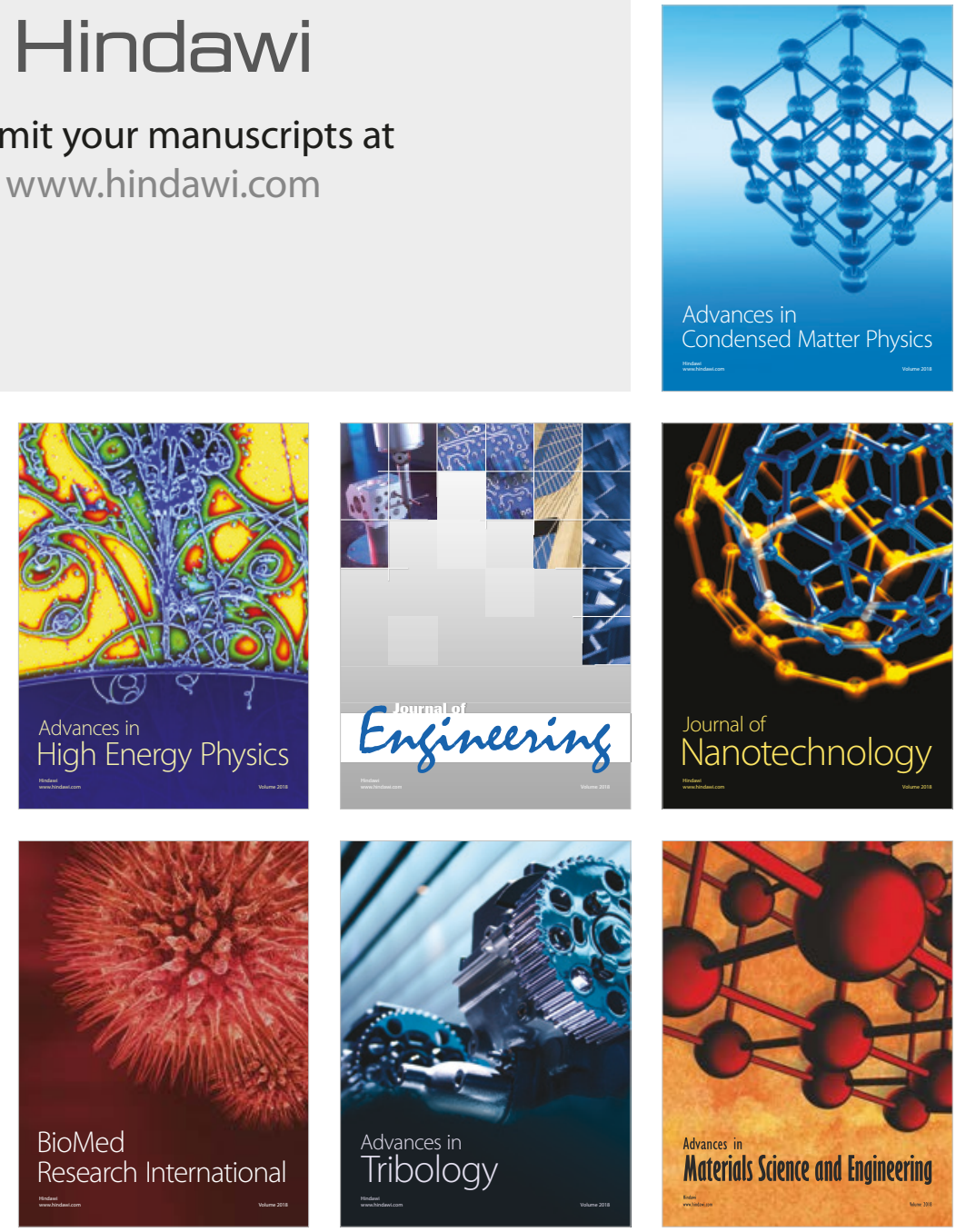